\title{
Fetal-Like Erythropoiesis during Recovery from Transient Erythroblastopenia of Childhood (TEC)
}

\author{
MICHAEL P. LINK ${ }^{(31)}$ AND BLANCHE P. ALTER \\ Division of Hematology and Oncology, Children's Hospital Medical Center and the Sidney Farber Cancer Institute, \\ and the Department of Pediatrics, Harvard Medical School, Boston, Massachusetts, USA
}

\begin{abstract}
Summary
Fetal-like erythropoiesis frequently accompanies marrow stress conditions such as Diamond-Blackfan syndrome and aplastic anemia. In contrast, patients with transient erythroblastopenia of childhood have erythrocytes which lack fetal characteristics at the time of diagnosis. This report describes nine children with transient erythroblastopenia of childhood in whom transient, fetal-like erythropoiesis was observed during the period of recovery. These patients initially presented with anemia, reticulocytopenia, erythrocytes of normal size for age, low levels of fetal hemoglobin, and i-antigen. During the recovery period, however, erythrocytes manifested one or more fetal characteristics. These included an increased fetal hemoglobin (in three of five patients), the presence of $i$-antigen (in four of six patients), and macrocytosis (in seven of nine patients). These fetal characteristics persisted more than 2 wk after the reticulocyte count returned to normal. Within one year from diagnosis, red blood cells contained no fetal characteristics.
\end{abstract}

\section{Speculation}

The observations reported here suggest that "fetal-like" red blood cell characteristics may represent a normal response pattern during recovery from marrow hypoplasia. If this hypothesis is correct, similar fetal erythrocyte characteristics should be present in red blood cells of patients recovering from marrow hypoplasia of various etiologies (e.g., hypoplastic crises complicating hemolytic anemias). The great variability in degree and duration of "fetal characteristics" may reflect differences in the regulation of the proliferating erythroid compartment during recovery among individual patients. Although the significance of "fetal-like erythropoiesis" during recovery remains to be defined, it may provide clues to the regulation of hemoglobin synthesis.

Fetal red blood cells differ from the erythrocytes produced after birth in several ways. Hemoglobin $F\left(\alpha_{2} \gamma_{2}\right)$, the major constituent of red cells during intra-uterine life, is replaced during infancy by hemoglobin $\mathrm{A}\left(\alpha_{2} \beta_{2}\right)$, and the minor adult hemoglobin $\mathrm{A}_{2}\left(\alpha_{2} \delta_{2}\right)$. Fetal erythrocytes are larger $\left(\mathrm{MCV}=140 \mu^{3}\right.$ at 20 wk gestation compared to $85 \mu^{3}$ in adults) and have shorter life spans than do their adult counterparts ( 80 days versus 120 days). The surfaces of adult erythrocytes express I-antigen, whereas fetal erythrocyte surfaces are characterized by i-antigen. Fetal red blood cells are also deficient in carbonic anhydrase and have characteristic levels of other enzymes (13). These fetal erythrocyte characteristics normally disappear during the first year of life. However, fetallike erythropoiesis reappears in older children and adults with a variety of hematologic disorders including bone marrow failure, as well as neoplastic and preneoplastic conditions. In juvenile chronic myelogenous leukemia, there is a progressive increase in fetal erythroid characteristics due to the expansion of a malignant clone of stem cells (21). Fetal-like erythropoiesis has also been found to occur during periods of bone marrow stress, either during bone marrow failure $(7,16)$ or in states of rapid bone marrow recovery from aplasia after bone marrow transplantation $(1,3$, 17). The term "fetal-like" is used because the erythrocytes may express only one and not all of the characteristics of fetal red blood cells.

To determine if fetal-like erythropoiesis accompanies bone marrow recovery from other hypoplastic states, we studied children with transient erythroblastopenia of childhood (TEC) from the time of presentation to full recovery. TEC is an unusual disease of infants and young children, characterized by the insidious onset of hypoproliferative anemia without decreases in leukocyte and platelet production. Although the anemia may be quite severe at presentation, rapid and complete recovery is the rule with permanent restoration of normal hematopoiesis $(2,11,19,23,25,26)$. Wang and Mentzer (20) demonstrated that patients with TEC have erythrocytes with "adult" characteristics at the time of diagnosis. We wished to determine whether these adult characteristics persisted during the recovery phase. Instead, we found that recovery in TEC is accompanied by transient fetal-like erythropoiesis.

\section{MATERIALS AND METHODS}

We studied all patients with a diagnosis of TEC who were seen at the Children's Hospital Medical Center between 1971 and 1978. There were three males and six females. Diagnosis was established on the basis of: (1) normocytic, normochromic anemia with absence of reticulocytosis; (2) absence and/or severe deficiency of erythroblasts in bone marrow aspirates with otherwise normal elements present; (3) lack of evidence of underlying hemolytic process or other hematologic disease before the onset of illness or after recovery; and (4) rapid and durable recovery of normal erythropoiesis. Clinical and laboratory information from $29 \mathrm{pa}-$ tients with Diamond-Blackfan syndrome (DBS) followed at Children's Hospital Medical Center during the same time period were reviewed for comparison $(1,2)$. These patients were characterized by chronic anemia of greater than 6 months duration requiring steroids and/or transfusions for several years-usually lifelong. All studies were approved by the Human Investigation Committee of the Children's Hospital Medical Center.

During follow-up, several parameters were assessed at frequent intervals. Blood counts, indices, and reticulocyte counts were measured with standard methods, and compared with age-appropriate normal values (24). Fetal hemoglobin was quantified by alkali denaturation (18). Numbers of cells containing fetal hemoglobin were assessed by the acid elution technique (10) using a kit purchased from Boehringer-Mannheim. Titer of red cell $i$-antigen reactivity was determined using five-fold dilutions of anti-i serum (Den) beginning with a $1 / 50$ dilution in saline (3). Adult blood is negative at $1 / 50$, and cord blood is positive at $1 / 1250$ to $1 / 1 / 250$ dilutions of the anti-i.

Age-related normal values for MCV were from Dallman and Siimes (6); alkali denaturation was from Colombo et al. (5) and ititer was from Marsh (12). 
Table 1. Data at the time of presentation of patients with TEC

\begin{tabular}{|c|c|c|c|c|c|c|c|c|c|c|c|c|c|}
\hline No. & Patient & Sex & $\begin{array}{c}\text { Age } \\
\text { (mos) }\end{array}$ & $\begin{array}{c}\mathrm{Hb} \\
(\mathrm{g} / \mathrm{dl})\end{array}$ & $\begin{array}{c}\text { Hemato- } \\
\text { crit } \\
(\%)\end{array}$ & $\begin{array}{c}\text { MCV } \\
\left(\mu^{3}\right) \\
\end{array}$ & $\begin{array}{c}\text { White } \\
\text { blood cells } \\
\text { per } \mathrm{mm}^{3}\end{array}$ & $\begin{array}{l}\text { Platelets } \\
\text { per } \mathrm{mm}^{3}\end{array}$ & $\begin{array}{c}\mathrm{Hb} \mathrm{F} \\
(\%)\end{array}$ & $\begin{array}{c}\mathrm{Hb} \mathrm{F} \\
(\mathrm{mg} / \mathrm{dl})\end{array}$ & i titer & $\begin{array}{c}\text { Acid- } \\
\text { resistant } \\
\text { cells }(\%)\end{array}$ & $\begin{array}{c}\text { Blood } \\
\text { type }\end{array}$ \\
\hline 1 & J. J. & $\mathrm{F}$ & 26 & 6.7 & 18.3 & 77 & 7,000 & 429,000 & 2.1 & 208 & $\mathrm{ND}^{1}$ & ND & $\mathrm{AB}+$ \\
\hline 3 & J. H. & $F$ & 32 & 4.5 & 12.8 & 80 & 11,900 & 653,000 & ND & ND & $<1 / 50$ & 0 & $A+$ \\
\hline 4 & S. G. & M & 20 & 5.8 & 16.3 & 79 & 9,500 & 423,000 & 3.2 & 186 & $<\mathrm{l} / 50$ & 4 & $0+$ \\
\hline 5 & J. M. & M & 27 & 9.0 & 25.1 & 78 & 8,500 & 460,000 & ND & ND & $<1 / 50$ & 2 & ND \\
\hline 8 & L. P. & $\mathrm{F}$ & 23 & 7.4 & 21.6 & 81 & 6,500 & 650,000 & ND & ND & $<1 / 50$ & 5 & ND \\
\hline 9 & B. T. & $\mathrm{F}$ & 19 & 6.1 & 17.1 & 81 & 9,100 & 701,000 & ND & ND & $<1 / 50$ & 1 & $\mathrm{AB}+$ \\
\hline
\end{tabular}

${ }^{1}$ N.D., not done.

\section{RESULTS}

Nine patients with TEC were studied. The data at the time of presentation are summarized in Table 1. Virtually all of the patients were in the second and third years of life. The range was from 19 to 41 months, and the mean was 27 months. The ages at the time of presentation of our patients with TEC and DBS are shown in Figure 1. The age peaks for DBS and TEC are obviously distinct; however, three patients with DBS presented between the ages of 18 months and 4 years, well within the TEC age range.

At the time of diagnosis, all eight patients in whom platelet counts were performed demonstrated mild-to-moderate thrombocytosis (Table 1). Although this finding remains unexplained, markedly elevated platelet counts are often found in DBS as well (2). All nine TEC patients had erythrocyte mean cell volumes that were normal for age. Levels of i-antigen were not increased, and levels of fetal hemoglobin were essentially normal for age. The previously noted association of TEC with blood group A (23) was not confirmed in this small study.

Six of nine patients were felt to be sufficiently symptomatic from their anemia to require a single transfusion of packed red cells (Table 2). Four patients were treated with prednisone for relatively short periods, but this did not seem to shorten the time to hematopoietic recovery. In all patients, reticulocytes appeared in the peripheral blood within 1 month of presentation and in four cases, within the first wk. Figure 2 shows the course of a representative patient who was transfused and treated with prednisone. Reticulocytes soon appeared and peaked at $3 \mathrm{wk}$. Total hemoglobin rose slowly. The MCV rose with the reticulocytes, but large cells for age persisted for more than 100 days. Fetal hemoglobin and i-antigen also rose and remained elevated for several weeks. Thus, the recovery of this patient was associated with a wave of fetal-like erythropoiesis which eventually disappeared.

Several patients were followed closely during the period of hematologic recovery. The data are shown in Table 2 and Figure 3. The patients had a short-lived but brisk reticulocytosis followed by normalization of hemoglobin levels and return of reticulocyte percentage to normal. The reticulocytosis was accompanied by a rise in the $\mathrm{MCV}$, which remained elevated in seven of eight patients long after the reticulocytes had disappeared and slowly returned to normal over a period of approximately 100 to 200 days. Three of five patients tested demonstrated an elevation in percentage of hemoglobin $F$ (by alkali denaturation) which followed the reticulocytosis. Three patients also had increased percentage of hemoglobin F-containing cells on acid elution preparations. Four of six patients tested had elevations in i-titer. The degree of anemia did not seem to affect the appearance of fetal characteristics during recovery because transfusions given to patients 6 and 9 did not abort the subsequent wave of fetal cells.

All patients for whom data were available (seven of nine) demonstrated at least one fetal characteristic during recovery, whereas the cells of patient 4 (S. G.) demonstrated all three of the evaluated fetal characteristics. Patients followed for more than one year had return of adult erythropoiesis with normalization of
AGE AT DIAGNOSIS

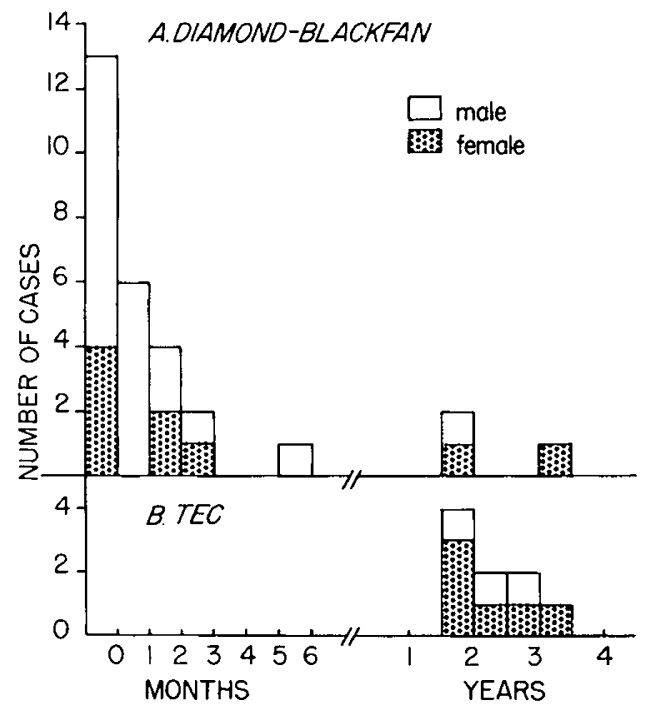

Fig. 1. Age at the time of diagnosis of 29 patients with DBS and nine patients with TEC. $\square$, male; 露, female.

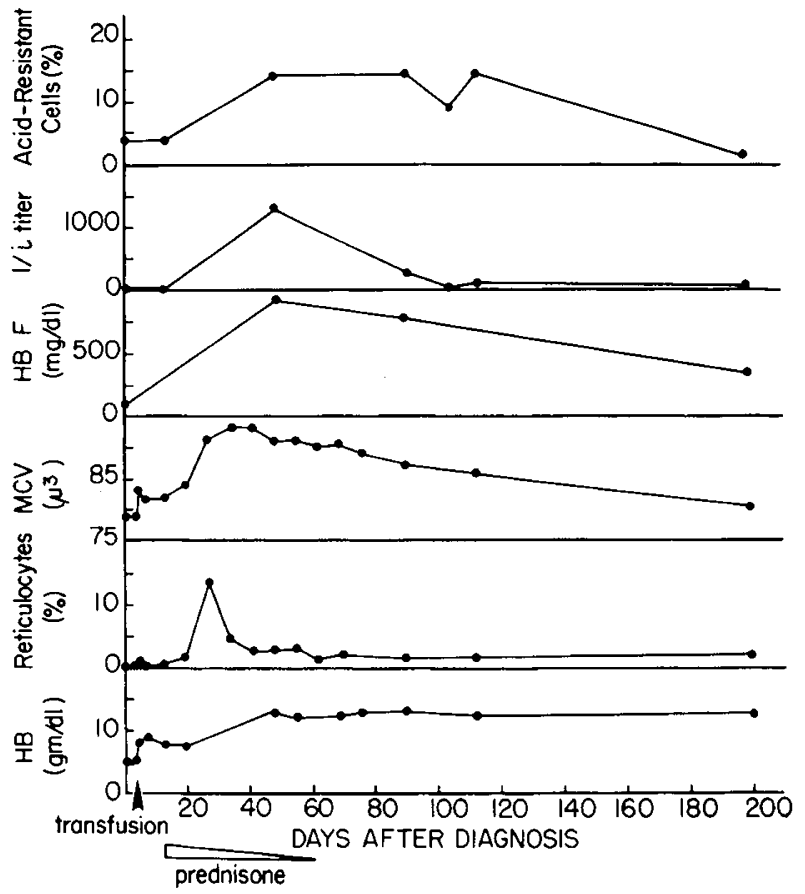

Fig. 2. The course of a representative patient (S. G.) recovering from TEC. $\uparrow$, transfusion. $\triangleright$, prednisone. 
Table 2. Data during recovery of patients with TEC

\begin{tabular}{|c|c|c|c|c|c|c|c|c|c|}
\hline No. & Patient & Transfusion & Prednisone & $\begin{array}{l}\text { Interval } \\
\text { to first } \\
\text { reticulocyte } \\
\text { response }\end{array}$ & $\begin{array}{l}\text { Maximum } \\
\operatorname{MCV}\left(\mu^{3}\right)\end{array}$ & $\begin{array}{c}\text { Maximum } \\
\% \mathrm{Hb} \mathrm{F}\end{array}$ & $\begin{array}{c}\text { Maximum } \\
\mathrm{Hb} \mathrm{F} \\
(\mathrm{mg} / \mathrm{dl})\end{array}$ & $\begin{array}{l}\text { Maximum \% } \\
\text { acid- } \\
\text { resistant } \\
\text { cells }\end{array}$ & $\begin{array}{c}\text { Maximum } \\
\text { i titer }\end{array}$ \\
\hline 1 & J. J. & + & $\begin{array}{l}1.5 \mathrm{mg} / \mathrm{kg} / \text { day for } 2 \\
\text { wk, then taper }\end{array}$ & 7 days & 90 & $\mathrm{ND}^{1}$ & ND & ND & ND \\
\hline 2 & C. H. & - & & 5 days & 95 & 5.2 & 525 & ND & ND \\
\hline 3 & J. H. & + & $\begin{array}{l}2 \mathrm{mg} / \mathrm{kg} / \text { day for } 2 \\
\text { wk }\end{array}$ & 7 days & 91 & ND & ND & 0 & $1 / 1250$ \\
\hline 4 & S. G. & + & $\begin{array}{l}2 \mathrm{mg} / \mathrm{kg} / \text { day for } 1 \\
\text { wk, then taper }\end{array}$ & 21 days & 93 & 6.9 & 883 & 14 & $1 / 1250$ \\
\hline 5 & J. M. & - & & ND & 83 & $\mathrm{ND}$ & $\mathrm{ND}$ & $\mathrm{ND}$ & $<1 / 50$ \\
\hline 6 & A. $G$. & + & $\begin{array}{l}2 \mathrm{mg} / \mathrm{kg} / \text { day for } 6 \\
\text { wk then taper }\end{array}$ & 31 days & 96 & 3.1 & 298 & 1 & $1 / 1250$ \\
\hline 7 & T. B. & + & 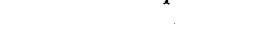 & ND & $\mathrm{ND}$ & $\mathrm{ND}$ & ND & ND & ND \\
\hline 8 & L. P. & - & & 6 days & 92 & 11.5 & 1265 & 15 & $1 / 50$ \\
\hline 9 & B. T. & + & & 10 days & 92 & 3.1 & 381 & 5 & $<1 / 50$ \\
\hline
\end{tabular}

${ }^{1} \mathrm{ND}$, not done; not followed.

TEC AT PEAK RESPONSE

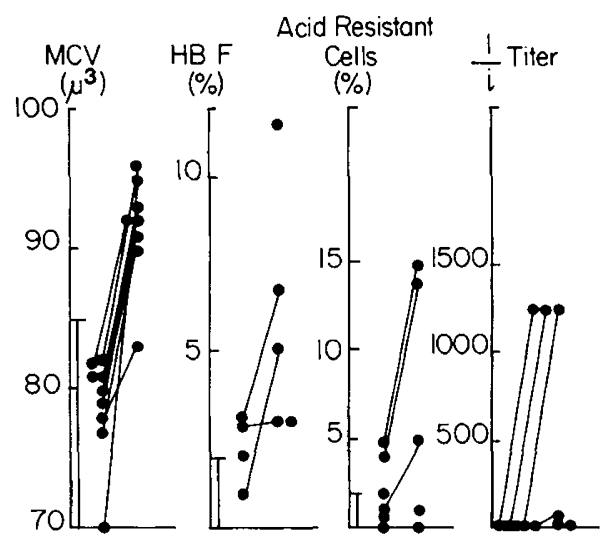

Fig. 3. Maximum values achieved by individual TEC patients for each of the red cell characteristics. ( $)$ compared to age-appropriate normal range (I). Values at presentation are on left, values at peak response on right. Lines connect individual patients.

MCV, disappearance of hemoglobin F and elevated i-titers; usually this normalization occurred within 6 months.

\section{DISCUSSION}

Red blood cells produced during periods of hematopoietic stress have been shown previously to exhibit fetal-like characteristics. We now show that patients recovering from TEC demonstrated similar fetal-like erythrocyte characteristics. In each case, production of fetal cells occurred at the onset of marrow recovery. The pattern of fetal characteristics was variable, but the duration of fetal-like erythropoiesis was always brief. Although some of the patients were treated with prednisone, it is unlikely that steroid therapy played any role in the stimulation of fetal-like erythropoiesis because similar fetal-like characteristics were seen in patients who were untreated. Furthermore, fetal-like erythropoiesis appears during bone marrow recovery from aplasia after bone marrow transplantation without steroid therapy (3). There is no evidence that the clinical course of these patients was altered by prednisone therapy, and we do not recommend steroid therapy in this disorder.

The patients with TEC clearly did not have DBS. The age of onset in TEC is later than in DBS. In TEC, $80 \%$ of cases present after one year of age (2), whereas $90 \%$ of those with DBS are diagnosed within the first year $(2,7)$. However, because of overlap, age alone is insufficient for a definite diagnosis.

None of the TEC patients had erythrocytes with fetal charac- teristics at the time of presentation. Wang and Mentzer (20) suggested that the absence of fetal characteristics could be used to distinguish patients with TEC from those with DBS. All of the patients with DBS in their series had erythrocytes with fetal characteristics, whereas only one of nine patients with TEC had elevated fetal hemoglobin, and one of five had an elevated iantigen score. In that report, TEC patients were studied at presentation, whereas DBS patients were studied during steroid-maintained remission. Our data suggest that attempts to distinguish between DBS and TEC on the basis of erythrocyte characteristics must be done only after consideration of the course of the disorder. Patients with DBS have fetal-like erythrocytes at all phases of their disease--at diagnosis, during recovery, and in steroid-maintained or spontaneous remission (2). Patients with TEC can be expected to develop fetal-like erythrocyte characteristics during recovery which are indistinguishable from those found in patients with DBS. In fact, the single TEC patient in the Wang and Mentzer series who had elevated i-antigen and fetal hemoglobin was recovering and exhibiting reticulocytosis.

The adult characteristics of erythrocytes of TEC patients at presentation contrast with the fetal parameters observed in patients with aplastic anemia, who come to medical attention with similar degrees of anemia and thus with equally "stressed" hematopoiesis. TEC may, in fact, result from a complete, albeit transient, cessation of erythropoiesis. Circulating erythrocytes which remain antedate the onset of the disease and demonstrate age-appropriate characteristics. In aplastic anemia, hematopoiesis continues although at a markedly reduced rate, and the fetal characteristics reflect the chronic limited marrow response to anemic stress. There is virtually no erythropoiesis in TEC until recovery, at which time there is a wave of stress erythropoiesis as the marrow is repopulated.

The dramatic burst of fetal-like erythropoiesis during recovery from TEC is short-lived. Apparently, only the initial wave of reticulocytes possesses the fetal characteristics. Shortly thereafter, there is a switch over to adult erythropoiesis, whereas the erythrocytes with fetal-like characteristics disappear within one red cell life span. Dover et al. (8) studied two patients with TEC by anti$\mathrm{F}$ single cell assays. Reticulocytes with hemoglobin $\mathrm{F}$ appeared early, matured into erythrocytes with hemoglobin F, and subsequently declined. Similar results were reported by Papayannopoulou et al. (15).

The appearance of fetal-like erythrocytes during recovery from hypoplastic states is the subject of current laboratory investigation. Erythroid stem cells which are preprogrammed to produce fetallike erythrocytes may have a selective advantage in repopulation of a hypoplastic marrow under the influence of high levels of erythropoietin. The intensive anemic stros may invoke rapid differentiation of primitive erythroid precursors that regularly express fetal hemoglobin and other fetal characteristics. The mar- 
row of one patient (patient 9) was cultured in vitro at the time of her presentation when reticulocytes were absent from the blood, and simultaneous bone marrow aspirates showed only scant erythroid activity. The proliferating marrow cells in plasma clot culture synthesized significant amounts of hemoglobin $\mathrm{F}$, in contrast with the absence of synthesis in cultured marrow cells from normal controls (4). This finding correlated well with the patient's clinical course; reticulocytosis began 1 wk later, and fetal characteristics appeared in the blood shortly thereafter.

There is evidence to suggest that the individual fetal characteristics do not necessarily appear on the same erythrocytes during stress erythropoiesis. Selective enrichment of "fetal" cells by agglutination with anti-i serum did not enrich for hemoglobin $F$ in a study of selected patients with marrow failure syndromes (1). Hillman and Giblett (9) noted the reappearance of "ii" without concomitant rise in fetal hemoglobin in patients stressed by phlebotomy. Thus, it is possible that fetal erythropoiesis in TEC patients may involve all or only some fetal features. However, Papayannopoulou et al. (14) used double immunofluorescence to detect hemoglobin $\mathrm{F}$ and i-antigen, and found simultaneous expression of these fetal features early in recovery of patients with TEC, although this concordance was lost later on. Our patients did not have synchronous expression of all fetal characteristics, but we may have missed the early concordance. Weatherall et al. (22) proposed that a population of F-cells persists in normal adults. So-called reactivation of hemoglobin $F$ synthesis results from differential growth of these cells. The early appearance of fetal-like characteristics during recovery from marrow hypoplasia results from the selective advantage retained by these F-cell precursors. It is unlikely that the reappearance of fetal-like erythropoiesis results from the selective expansion of a single clone of F-cells. Stress erythropoiesis may, in fact, result in the expansion of several fetal-like clones, the progeny of each demonstrating one or more fetal characteristics. The control mechanism governing the appearance of each of the fetal features and possible interactions among them remains to be elucidated.

\section{REFERENCES AND NOTES}

1. Alter, B. P.: Fetal erythropoiesis in bone marrow failure syndromes, In: G. Stamatoyannopoulos, A. Nienhuis: Cellular and Molecular Regulation of Hemoglobin Switching. Pp. 87-105 (Grune \& Stratton, Inc, New York, 1979).

2. Alter, B. P.: Childhood red cell aplasia. Am. J. Pediatr. Hematol./Oncol., 2:121 (1980).

3. Alter, B. P., Rappeport, J. M., Huisman, T. H. J., Schroeder, W. A., and Nathan, D. G.: Fetal erythropoiesis following bone marrow transplantation. Blood, 48: 843 (1976).

4. Clarke, B. J., Nathan, D. G., Alter, B. P., Forget, B. G., Hillman, D. G., and Housman, D.: Hemoglobin synthesis in human BFU-E- and CFU-E-derived erythroid colonies. Blood, 54: 805 (1979).

5. Colombo, B., Kim, B., Perez-Atencio, R., Molina, C., and Terrenato, L.: The pattern of fetal haemoglobin disappearance after birth. Br. J. Haematol., 32: 79 (1976).

6. Dallman, P. R., and Siimes, M. A.: Percentile curves for hemoglobin and red cell volume in infancy and childhood. J. Pediatr., 94: 26 (1979).

7. Diamond, L. K., Wang, W. C., and Alter, B. P.: Congenital hypoplastic anemia. Adv. Pediatr., 22: 349 (1976).
8. Dover, G. J., Boyer, S. H., and Zinkham, W. H.: Production of erythrocytes that contain fetal hemoglobin in anemia. J. Clin. Invest., 63: 173 (1979)

9. Hillman, R. S., and Giblett, E. R.: Red cell membrane alteration associated with "marrow stress." J. Clin. Invest., 44: 1730 (1965).

10. Kleihauer, E., Braun, H., and Betke, K.: Demonstration von fetalem Hämoglobin in den Erythrocyten eines Blutausstrichs. Klin. Wochenschr., 35: 637 (1957).

11. Lovric, V. A.: Anaemia and temporary erythroblastopenia in children. Aust. Ann. Med., 19: 34 (1970).

12. Marsh, W. L.: Anti-i: a cold antibody defining the Ii relationship in human red cells. Br. J. Haematol., 7: 200 (1961).

13. Oski, F. A., and Naiman, J. L.: Hematologic problems in the newborn. Ed 2, pp. 98-100 (W. B. Saunders Company, Philadelphia, 1972).

14. Papayannopoulou, T., Maniatis, A., and Stamatoyannopoulos, G.: Simultaneous assessment of i-reactivity and fetal hemoglobin in individual cells by double immunofluorescent labeling. Blood, 52 (Suppl 1): 117 (1978).

15. Papayannopoulou, T., Vichinsky, E., and Stamatoyannopoulos, G.: Fetal hemoglobin production during acute erythroid expansion. I. Observations in patients with transient erythroblastopenia and post-phlebotomy. $\mathrm{Br}$. J. Haematol., 44: 535 (1980).

16. Shahidi, N. T., Gerald, P. S., and Diamond, L. K.: Alkali resistant hemoglobin in aplastic anemia of both acquired and congenital types. N. Engl. J. Med., 266: 117 (1962).

17. Sheridan, B. L., Weatherall, D. J., Clegg, J. B., Pritchard, J., Wood, W. G. Callender, S. T., Durant, I. J., MeWhirter, W. R., Ali, M., Partridge, J. W., and Thompson, E. N.: The patterns of fetal haemoglobin production in leukaemia. Br. J. Haematol., 32: 487 (1976).

18. Singer, K., Chernoff, A. I., and Singer, L.: Studies in abnormal hemoglobins. I Their demonstration in sickle cell anemia and other hematologic disorders by means of alkali denaturation. Blood, 6: 413 (1951).

19. Tillmann, W., Prindull, G., and Schröter, W. S.: Severe anemia due to transient pure red cell aplasia in early childhood. Eur. J. Pediatr., 123: 51 (1976).

20. Wang, W. C., and Mentzer, W. C.: Differentiation of transient erythroblastopenia of childhood from congenital hypoplastic anemia. J. Pediatr., 88: 784 (1976).

21. Weatherall, D. J., Clegg, J. B., Wood, W. G., Callender, S. T., Sheridan, B. L., and Pritchard, J.: Fetal erythropoiesis in human leukaemia. Nature (Lond.), 247: 710 (1975)

22. Weatherall, D. J., Clegg, J. B., and Wood, W. G.: A model for the persistence or reactivation of fetal haemoglobin production. Lancet, 2: 660 (1976).

23. Wegelius, R., and Weber, T. H.: Transient erythroblastopenia in childhood. Acta Paediatr. Scand., 67: 513 (1978).

24. Wintrobe, M. W., Lee, G. R., Boggs, D. R., Bithell, T. C., Athens, J. W., and Foerster, J.: Clinical Hematology. p. 1797 (Lea \& Febiger, Inc., Philadelphia, 1974).

25. Wranne, L.: Transient erythroblastopenia in infancy and childhood. Scand. J. Haematol., 7: 76 (1970).

26. Wranne, L., Bonnevier, J. O., Killander, A., and Killander, J.: Pure red cell anemia with pro-erythroblast maturation arrest. Scand. J. Haematol., 7: 73 (1970)

27. This study was presented in part at the American Pediatric Society, Atlanta, May, 1979, and appeared in abstract form in Pediatr. Res. 13: 435 (1979).

28. The present address of Dr. Michael P. Link is: Department of Pediatrics, Stanford University School of Medicine, Stanford, CA.

29. The present address of Dr. Blanche P. Alter is: Division of Hematology, Mt Sinai School of Medicine, New York, NY.

30. The authors are grateful to Drs. David G. Nathan and Bertil E. Glader for stimulating discussions and critical evaluation of the manuscript and to the House Staff and Fellows of the Children's Hospital Medical Center who cared for the patients. We thank Marie Crookston for the anti-i serum.

31. Requests for reprints should be addressed to: Michael Link, M.D., Division of Hematology/Oncology, Children's Hospital at Stanford, Palo Alto, CA 94304 (USA).

32. This research was supported by National Institutes of Health grant no. R01-AM15322. Dr. Alter is the recipient of National Institutes of Health Research Career Development Award K04-HL-00177.

33. Received for publication August 14, 1980

34. Accepted for publication October 7, 1980. 